\title{
A MULHER/ENFERMEIRA NOS ÂMBITOS DOMÉSTICO-FAMILIAR E PÚBLICO uma abordagem teórica-contextual
}

\author{
Maria Itayra Coelho de Souza Padilha*
}

PADILHA, M.I.C. de S. A mulher/enfermeira nos âmbitos doméstico-familiar e público - uma abordagem tébrica-contextual. Rev.Esc.Enf.USP, v.29, n.3, p. 246-60, dez. 1995.

O esiudo trata da evolução histórica da mulher na sociedade, em particular nos aspectos familiar e público. Pretende-se estabelecer uma relação entre o papel desempenhado pela mulher, através dos tempos, e a enfermagem, uma profissão eminentemente feminina.

UNITERMOS: Exercício da Enfermagem. Mulheres-Enfermeiras.

Mulher-História.

\section{INTRODUÇÃO}

A evolução social da mulher desde a Grécia até a atualidade, vem sendo registrada historicamente como uma situação de dependência, submissão e inferioridade.

BADINTER $^{3}$ em sua obra diz que:

"O homem e a mulher se completam tão bem, que juntos são quase todo-poderosos: senhores da vida, artesãos de sua sobrevivência, de seu prazer e do calor afetivo necessário, sem o que o humano se deteriora, porém separados são inúteis, sem sentido de existir."

Embora a complementaridade dos sexos seja evidente anatomicamente, não o é em suas funções, verificando-se que, em toda sociedade humana, sempre existiram tarefas reservadas a um sexo e proibidas ao outro.

A mulher grega, diz $\mathrm{NETO}^{22}$, em especial a ateniense não tinha direito público, necessitando do pai, marido ou herdeiro para serem seus tutores

\footnotetext{
* Professora Assistente do Departamento de Metodologia da Enfermagem da EEAN/UFRJ. Mestre em Administração de Enfermagem. Livre-Docente em exercício da Enfermagem.
} 
jurídicos, e mesmo recebendo um dote ao casar, este não podia ser administrado por cla.

Sua vida era limitada ao lar, ao Gineceu*. Não era considerada cidadã, sendo antes, esposa ou filha de um cidadão.

$\mathrm{PRADO}^{30}$ refere a existência dos "gyneconomes", que era uma instituição social com poderes especificos de reprimir todas as manifestaçōes civis ou religiosas das mulheres.

O casamento era monogâmico, porém segundo ENGELS ${ }^{14}$ a poligamia era aceita para os homens como normal. $\Lambda$ principal obrigação da mulher grega era a clausura, pois sair de casa sem autorização prévia do marido era um delito tão grave quanto o adultério. Enfim, a mulher grega era destinada a cuidar da casa aprendendo apenas a fiar, tecer, coser e procriar os filhos. O homem tinha os seus exercícios ginásticos e suas discussões públicas, ações de que a mulher estava excluida.

De acordo com ENGELS"1 as únicas mulheres das quais os antigos falam com consideração são as casadas espartanas e a elite das hetairas ${ }^{5}$. As primeiras pelo seu caráter e liberdade de costumes, e as segundas pelo seu talento e cultura. Ainda segundo o autor:

"O primeiro antagonismo de classes que apareceu na história coincide com o desenvolvimento do antagonismo entre o homem e. a mulher na monogamia: e a primeira opressão de classes, com a opressão do sexo feminino pelo masculino."

A familia monogâmica não se revestiu, em todas as épocas e lugares, da forma clássica e rígida que teve entre os gregos. Entre os romanos, a mulher era mais livre e considerada, podendo inclusive romper o compromisso matrimonial a sua vontade, como o homem. "O romano acreditava suficientemente garantida a fidelidade de sua mulher pelo direito de vida e morte que tinha sobre cla" (ENGELS ${ }^{14}$ ).

Isto significa que a mulher mantinha sua inferioridade ao homem, estando excluída das funçōes públicas, políticas e administrativas. $\Lambda$ liberdade conforme $\mathrm{MACEDO}{ }^{18}$ dependia de sua posição na sociedade e mesmo quando juridicamente livre, tinha a sua autonomia limitada pelos interesses da familia. Isto é reforçado por BADINTER ${ }^{3}$ quando diz que ao casar a mulher, o pai transmitia todos os seus dircitos ao esposo.

Para ENGELS ${ }^{14}$, o maior progresso no desenvolvimento da monogamia ocorreu com a entrada dos germanos para a história. Isto foi verificado a partir da obra "Germânia" escrita por Tácito, o grande historiador romano do século I D.C.

\footnotetext{
* O Gineceu era a parte da habitaçño grega destinada às mulheres.
} 
O matrimônio era santificado e a poligamia so existia para os grandes e os chefes da tribo: a passagem do direito materno para o paterno devia terse realizado recentemente, pois o irmão da mãe (no matriarcado) quase era tido como um parente mais proximo que o pai; as mulheres gozavam da mais elevada consideração e exerciam grande influência, até nos assuntos públicos, o que se opõe ao poder masculino da monogamia.

$M$ ACEDO ${ }^{18}$ diz que Tácito exaltou a austeridade e força moral da mulher, bem como sua vitalidade mesmo nas guerras, o seu companheirismo e submissão em relação aos homens.

$O$ poder feminino se resumia no âmbito doméstico, já que não tinha poder jurídico. Quando contraía matrimônio recebia um dote do marido e do pai (bens móveis e imóveis). Tinha a propriedade, mas nunca a posse.

ENGEIS ${ }^{14}$ complementando, coloca que, quando os interesses da transmissão por herança fizeram nascer o poder paterno e da monogamia, o casamento dependia inteiramente de interesses econômicos.

Conforme $\mathrm{MELO}^{22}$ :

"A influência da ascensão do direito romano como estatuto jurídico a ser seguido pela nova estruturaç̃o do poder na Europa foi causa determinante do crescente processo de confinamento doméstico feminino e da supremacia da família patriarcal consolida-a o século XVI."

A maioria das mulheres que se distinguiram neste periodo através da arte e da literatura o fizeram por serem cortesãs, libertas espiritual e economicamente dos homens.

Muitas mulheres foram vítimas da Inquisição por deterem o saber e exercerem as práticas de saúde, atendendo as populações em geral. Este período foi denominado de "Caça às Bruxas", sendo paralelo à revolução científica (1500-1700), período em que as mulheres, a natureza e a sociedade eram consideradas "incontrolaveis, perigosas e cabticas" 30.

Dois movimentos que ocorreram nesse periodo, foram fundamentais para implementar novas mudanças nas relações sociais, polfticas e estruturais, levando ao processo de acumulação capitalista: a revolução iniciada na Inglaterra e o movimento social que culminou na Revolução Francesa de 1789.

Com o advento da maquinaria, MELO $0^{22}$ indica que houve um aproveitamento da mão-de-obra feminina e infantil, mais barata, mantendo o mesmo ritmo de produção. Essa incorporação tornou-se necessária para o operariado, como forma de garantir a sobrevivência do núcleo familiar.

Contudo, sob a dominação masculina, a mulher trabalhadora era ainda mais explorada que os trabalhadores homens, recebendo em média $50 \%$ a menos que eles, pelo mesmo trabalho. SAFFIOTI ${ }^{31}$, em análise relativa à 
industrialização e o emprego feminino, sustenta que apesar do trabalho na fábrica, a mulher continua a desempenhar seu trabalho em casa, estabelecendo com isso a dupla jornada, transformando o seu cotidiano em algo extenuante, porém inquestionável. BLAY ${ }^{8}$ reforça esta análise sobre o trabalho industrial e doméstico, dizendo que:

"Na sociedade burguesa o duplo papel econômico da mulher aparece ao nivel da consciência social através de uma ideologia que justifica e glorifica o trabalho doméstico e que endossa o trabalho industrial."

No século XIX enquanto as mulheres operárias dividiam com seus maridos a lida diária, na indústria têxtil e/ou cafeeira, as mulheres de classe social mais clevada eram exortadas a permanecerem em casa, sendo desestimuladas a buscarem qualquer tipo de instrução. Este é o modelo padrão da burguesia, onde o homem tem direito aos serviços domésticos da mulher, e esta deve manter-se submissa e fiel.

Enquanto os filhos varões das famílias burguesas iam a Europa receber educação e, conseqüentemente, estar $\mathrm{cm}$ contato com as novas idéias que fervilhavam, as mulheres permaneciam alheias em seu mundo, sendo inclusive restrita sua participação nos processos da época (D'ÁVILA NETO ${ }^{12}$ ).

PRADO $^{30}$ evidencia que essa pretensa ociosidade contribuiu para a divulgação de uma esposa-mulher das familias bem sucedidas economicamente; manter uma esposa era um privilégio; o trabalho da mulher fora do lar denotava pobreza familiar e fracasso do marido.

Mais uma vez ENGELS ${ }^{44}$ nos auxilia a entender as relaçōes sociais quando estabelece que o governo do lar transformou-se em serviço privado: a mulher converteu-se na primeira criada, sem participação na mais valia da produção social. Só a grande indústria dos nossos dias lhe abriu de novo embora apenas para a proletária, o caminho da produção social. Finaliza dizendo (jue "a família individual moderna baseia-se na escravidão doméstica, franca ou dissimulada da mulher e a sociedade moderna te uma massa cujas moléculas são famílias individuais".

No século XX muitas coisas mudaram para as mulheres. Não existe obrigatoriedade do casamen to e de sua manutenção, há um aumento crescente de mulheres estudando e trabalhando, mulheres representam mulheres nas lutas políticas, ideologicas e melhoria de condições de trabalho e de vida, etc.

Mas apesar disto, faço minhas as palavras de BELOT"I'I quando diz que arrebentar a cadeia de condicionamentos que se vai transmitindo de geração a geração não é uma tarefa simples, mas existem momentos históricos em que tais operações podem resultar mais fáceis que noutros. Estes momentos surgem de grandes crises, como as que hoje os valores da sociedade enfrentam e entre estas, o mito da "natural" superioridade masculina em contraposição à "natural" inferioridade feminina. 
Como em todo o mundo, no Brasil, o movimento pela libertação das mulheres foi encabeçado também por mulheres que, cada uma a scu modo, estiveram a frente dos cosstumes e padrões da sua êpoca.

Uma delas foi Bertha Lutz citada por D'ÁVIL $\Lambda$ NETO $^{12}$ que já em 1918 assumiu a liderança do movimento feminista no Brasil, tendo lutado em favor do direito do voto para as mulheres e contra a incapacidade civil da mulher casada.

Contudo, foi no fim da década de 60 como enfatizam BADIN'TER ${ }^{3}$, MURARO $^{24}$, MIRANDA $^{23}$, que os movimentos feministas e de emancipação feminina explodiram no mundo. Na França, elas se diriam tão exploradas quanto os colonizados de on tem, pelo homem branco. Nos Estados Unidos, sob a direção de Betty Friedman, comparavam a sua sorte a da comunidade negra.

Esta nova prática tanto na vida pública quanto privada, fez as mulheres perceberem quão profundos eram os valores patriarcais no seu cotidiano, nas atitudes, nas estruturas públicas na ciência, na economia e na política.

MACH $A D O^{12}$ verificou que mais de $50 \%$ das matrículas universitárias são femininas, questionando ainda as areas escolhidas pelas mulheres declarando que:

"boa parte delas encaminha-se para a pedagogia, psicologia, letras, enfermagem, servico social, profissões sabidamente de pouco "prestígio" e de baixa remuneração no mercado de trabalho, isto é, ligadas a servicos que gravitam em tormo das atividades domésticas, de nutrição, limpeza e vestuário".

PRADO ${ }^{30}$ reforça afirmando que o mercado de trabalho mantém uma delimitação precisa de empregos femininos e masculinos, tanto na horizontal (setores de atividade) como na vertical (hierarquicamente). Em 1981, conforme MURARO ${ }^{24}$, $51 \%$ das mulheres economicamente ativas ganhavam até um salário mínimo, enquanto que apenas $7 \%$ ganhavam entre 10 e 20 salários mínimos.

O setor saúde expandiu seu processo de feminização nos últimos anos, além daquelas profissões que tradicionalmente são formadas por um contingente quase que totalmente feminino, como por exemplo, a de Enfermagem e Serviço Social. MACHAD)( ${ }^{19}$ refere-se a agregação de mulheres às profissões que eram historicamente exercidas por homens, como a Medicina e a Odontologia.

$\Lambda$ inserção da mulher no mercado de trabalho e na política é essencial para a sua emancipação e crucial para a sua sobrevivência, já que a "dupla jornada" de trabalho permanece, tendo a mesma que conciliar o trabalho profissional-político com o trabalho doméstico (cuidado dos filhos, da casa, do marido e das pessoas de risco, como idosos, doentes crônicos e com problemas mentais, etc.). 
$\Lambda$ escolha de profissões ditas femininas articula o trabalho profissional com o trabalho doméstico, confundindo as duas esferas, privada e pública, fazendo com que a mulher não as distinga uma da outra.

ROGERS $^{30}$ coloca sua percepção das diferenças entre a mulher profissional e a mulher esposa em sua família, dizendo que:

"() termo "mulher profissional" era pejorativo em nossa casa. Significava ser fria, não feminina, não material, competitiva e agressiva. O papel de esposa consistia em ser emocionalmente apoiadora, fazer tudo o que fosse possivel para promover as idéias e a carreira do marido".

Na esfera política, a partir da década de 70 , houveram mudanças importantes na participação feminina, seja em movimentos sociais alternativos, seja em nível de estruturas partidárias ou em movimentos sindicais das várias categorias profissionais.

Com relação a participação da mulher nas políticas de saúde, a Conferência Nacional "Saúde e Direitos da Mulher" ", realizada em Brasília, 1986, resultante da sintese das Conferências estaduais foi um marco para a consolidação dos direitos da mulher, quando concluiu que saúde está relacionada à existência de um trabalho estável e condignamente remunerado. As mudanças requerem um trabalho lento e árduo para se efetivarem na prática, mas cada passo é uma nova vitoria alcançada.

\section{A ENFERMEIRA E O SER MULHER}

Uma revisão bibliográfica mostra que o status da mulher na sociedade e o grau de participação desta na vida pública e privada, sofreu muitas transformações com o passar do tempo, tendo uma influência decisiva no desenvolvimento da enfermagem, em todos os aspectos.

Simone de BE $A U V O I R^{6}$ muito inteligentemente coloca que "não se nasce mulher, torna-se mulher" e em contrapartida na enfermagem o que se ouve e diz aos quatro ventos é que "as enfermeiras nascem, não se fazem", já que a enfermagem te uma vocação nata. NIGIITINGALE ${ }^{26}$ refletindo sobre o significado de "sentir vocação" para alguma coisa, diz que:

"ser enfermeira é execular o trabalho conforme o seu próprio e elevado conceito do que é certo e o melhor para o doente, não apenas para cumprir ordens, mas para sua própria satisfação. Porque, se a enfermeira não o fizer para sua salisfacão pessoal. de nada adiantará ensiná-la e dizer-lhe que o faca." 
Florence Nightingale é considerada a precursora da Enfermagem moderna em todo o mundo, obtendo projeção maior a partir de sua participação como voluntária na Guerra da Criméia*, em 1854, quando com 38 mulheres (irmãs anglicanas e católicas) organizou um hospital de 4000 soldados internos, baixando a mortalidade local de $40 \%$ para $2 \%\left(\mathrm{P} \Lambda \mathrm{IXA} \mathrm{O}^{27}\right.$ ). Com o prêmio recebido do governo inglês, por este trabalho, fundou a primeira escola de enfermagem no Ilospital St. 'Thomas, em Londres, a 24.06.1860, com 15 candidatas.

De acordo com NASH" : "A casa devia funcionar como um colégio, onde reinasse um elevado espírito de enfermagem, num clima de se dar plenamente e de se tornar útil".

NIGHTINGALE" dizia que utilizou "a palavra enfermagem por falta de outra melhor", considerando-a como arte e devendo incluir condições tais que, por si mesmas, tornassem possível o assistir em enfermagem. Quanto ao trabalho da enfermeira, PAIX $\tilde{\Lambda})^{27}$ incorpora três elementos principais: "Espírito de Serviço (ou ideal). Habilidade (arte) e Ciência. Estes já haviam sido sustentados por Florence quando colocava a idéia da enfermagem como "arte, com motivação religiosa, exigindo estudos e aperfeiçoamento constantes, exercendo influência moral pelo que delas emana, quase sem que o percebam" (NASH ${ }^{25}$ ).

Nas "Notas sobre Enfermagem", NIGHTINGALE ${ }^{26}$ se refere aos aspectos que a enfermagem "deve ser" e facilmente podemos correlacionar com o mesmo "espera-se" da mulher. Fntão vejamos:

"Toda enfermeira deve ser uma pessoa com quem se pode contar, isto é, capaz de ser uma enfermeira "de confianca". (...) Deve ser estritamente sóbria, honesta e, mais do que isso, ser uma mulher religiosa e devolada. (...) Deve ser uma observadora segura, direta e rápida, e ser uma mulher de sentimentos delicados e modestos."

Para Nightingale, a enfermagem era tanto uma vocação como uma profissão e os dois aspectos deviam estar unidos, sendo que a seu ver qualquer mulher poderia vir a ser uma boa enfermeira.

Ao rever documentos sobre a origem da enfermagem prática no Brasil, encontramos alguns nomes como precursores, na figura de escravos, boticários, curandeiros e jesuítas, aqui na figura destacada de José de Anchieta, quando de acordo com P'AIXÃO ${ }^{27}$, este não se limitava à catequese,

\footnotetext{
* Antes deste evento Florence já estava se tornando conhecida na Inglaterra como uma mulher de força e personalidade notáveis,além de idealista e possuidora de uma capacidade invulgar.
} 
mas também atuava como "professor, médico e enfermeiro", deixando inclusive depoimentos escritos de sua terapêutica. Existem poucas referências ao trabalho desempenhado pelas mulheres na área de enfermagem, a não ser nas figuras das parteiras e curandeiras, sendo que o trabalho feminino institucionalizado da enfermagem se deu a partir do século XVIII, com a chegada das religiosas ao Brasil e a elas sendo entregues os estabelecimentos de assistência.

GERMANO ${ }^{16}$ e SILV ${ }^{34}$ admitem que o sentimento de religiosidade marcou parcialmente o desenvolvimento da enfermagem ate os dias de hoje quando alia-se a este, àquelas qualidades desejadas, tanto para a religiosa quanto para a enfermeira, como "obediência, respeito à hierarquia, humildade, etc.".

No período colonial, quando a mulher não tinha direitos a cidadania, era confinada ao lar cuidando da casa, dos filhos e empregados, exercendo o papel de conservadora da saúde dos elementos da família.

De certo modo, o papel das religiosas exercia influência nas mulheres da época já que quase não podiam opinar sobre nada além do domínio doméstico e deveriam se submeter a dominação do marido, em continuidade a do pai; porém, verifica-se o aparecimento de algumas viúvas no espaço público da saúde, que buscavam exercer uma "vida útil" após a perda dos maridos, cuidando dos doentes, como foi o caso de Francisca de Sande, Ana Nery e outras como relatam PAIXÃO ${ }^{27}$ e PIRES ${ }^{29}$.

Ao lado do carater religioso, a cnfermagem também foi influenciada por regras organizacionais do tipo militar. BARNES ${ }^{4}$ diz que as enfermeiras c os soldados têm em comum, o con tato com o perigo e com a angústia que ele provoca, utilizando como alívio a regra de não deixar nada ao acaso. Os deveres devem ser cumpridos com exatidão e pontualidade, seguindo rigorosamente as regras estabelecidas, havendo uma obsessão pela rotina, ordem e precisão.

Não se cogitava ainda o preparo de profissionais, já que as funções de enfermeira eram relegadas ao plano doméstico ou religioso, sem nenhum caráter técnico ou científico.

A primeira escola de enfermagem a ser fundada no Brasil foi a Alfredo Pinto, em 1890. Tinha como objetivo "preparar enfermeiros e enfermeiras para os hospícios e os hospitais eivis e militares". A sua criação, conforme PIRES $^{29}$, foi decorrente de conflitos entre os médicos do Hospício Nacional de Alienados e as religiosas que lá trabalhavam. () modelo foi baseado no da Escola de Salpetrière francesa e dirigido e organizado por médicos.

FOUCAULT ${ }^{15}$ comprova este dado em estudo sobre a incorporação do hospital a prática moderna acrescentando que 
"Com a aplicação da disciplina do espaço médico e pelo fato de que se pode isolar cada indivíduo, instalá-lo em uma cama, prescreverlhe uma dieta, etc., pretende-se chegar a uma medicina individualizante. Com efeito, é o individuo que será observado, vigiado, conhecido, curado. O individuo surge como objeto do saber e da prática médica."

O primeiro passo para a implantação da enfermagem no Brasil baseada no modelo nightingaleano, partiu de Carlos Chagas que, à frente do Departamento Nacional de Saúde Pública, em 1921 solicitou colaboração da Fundação Rockfeller para que fossem enviadas ao Brasil enfermeiras americanas, a fim de prepararem enfermeiras visitadoras, para atender a necessidade de saúde da época. () curso foi organizado, entre outras, por Ethel Parsons, a qual esteve à frente da criação da Escola de Enfermagem do Departamento Nacional de Saúde Pública em 1923, atual escola Anna Nery (PAIXÃO ${ }^{27}$ ), estabelecendo os requisitos necessários para fazer o curso de enfermagem:

"Ser mulher; ser diplomada por uma Escola Normal ou ter estudos equivalentes; apresentar um atestado firmado por médico da Saúde Pública avalisando as condições de saúde física, mental e ausência de defeitos físicos da candidata: ter entre 20 e 35 anos; apresentar referências de boa conduta, sendo que seria levado em consideração a experiência da candidata em direção de casa, no servico educativo e comercial." (PIRES' $\left.{ }^{29}\right)$

Inicialmente, de acordo com ALCÂNTARA', Ethel Parsons hesitou em utilizar a palavra "Enfermeira" devido a conotação negativa da mesma na época, preferindo o termo "nurse", a fim de diferenciar as profissionais formadas sob sua orientação das demais existentes na sociedade, porém o termo não teve aderência, prevalecendo as formas de denominação diferencial como enfermeira de alto padrão, de saúde pública ou simplesmente diplomada, as quais indicavam a nova categoria e permanecendo até hoje.

De lá para cá muita coisa mudou tanto na enfermagem, quanto nos conceitos do ser mulher.

A mulher saiu de casa e enfrentou o mercado profissional, assumindo o duplo encargo de trabalho, criando filhos, administrando empregadas e investindo na realização de seu ideal profissional.

O espírito de abnegação e doação tão propagado originariamente na enfermagem, vem sendo substituído pelo esforço de algumas enfermeiras em mostrar que esta é uma profissão com características específicas. Acreditamos que um dos entraves da enfermagem para atingir o status de profissão plena é proveniente da subestimação da mulher e do valor de seu trabalho, como mais-valia na sociedade. $\Lambda$ história da submissão e sujeição da mulher ao homem, dificulta a sua entrada igualitária na vida profissional, e faz com 
que muitas mulheres sejam profissionalmente conservadoras, inclusive as enfermeiras. IDI $\mathrm{LASCIO}^{13}$ diz que mulheres assumem posições sociais e políticas muito estreitas, devotando atenção, não para mudar a ordem social, porém a problemas limitados, relacionados com o seu próprio desenvolvimento educacional e profissional. "Em geral procuram aprovação, não liberação."

SANTOS;VIEIRA ${ }^{33}$ dizem que "ao nível de mercado de trabalho a enfermagem não é identificada como profissão, mas sim, como força de trabalho assalariada, que executa parcelas simples do processo produtivo". O que de certo modo se contrapõe ao que a clientela, médicos e a própria equipe de enfermagem esperam da enfermeira, isto $c$, que esteja sempre pronta a atender suas necessidades, a saber de tudo o que ocorre a sua volta e a ser capaz de fazer tudo o que for preciso para o bom funcionamento do setor de saúde.

BARNES 4 revela que os médicos vão às enfermarias em alguns momentos e com propositos definidos, já, as enfermeiras estão lá constantemente. Onde há doentes há enfermeiras e, sejam quais forem as suas necessidades, espera-se que as enfermeiras as satisfaçam.

Acreditamos que é necessário que se faça a retomada da enfermagem enquanto conceituação para entender e transpor os conflitos da atualidade: cuidado direto $X$ administração da assistência; educação continuada $X$ burocratização; vida doméstica $X$ vida profissional.

SOUZA ${ }^{35}$ define enfermagem como "uma arte e ciência que visa ao paciente como um todo: corpo, mente e espírito: técnica de enfermagem é aplicação dos conhecimentos dessa arte e ciência”.

O saber de enfermagem é um saber transcendental na medida em que é expresso sob a forma de arte produtiva e não tem como ser diferente, na medida em que o exercício da enfermagem como profissão aplica a ciência e a tecnologia como instrumental de delimitação da ação/arte, como forma de expressão, oriunda do nível de sensibilidade, de criação de cada exercente.

CARVALHO;CASTRO ${ }^{11}$ em artigo sobre a prática da enfermagem colocam que:

"A prática resume o significado de uma profissão na sociedade. Porque nela se consubstancia a realização do compromisso social, o qual, sendo obrigatório e coletivo, garante à profissão sua continuidade no tempo".

Complementando estas idéias, acredito que a prática de enfermagem não pode ser analisada de forma desvinculada da história de vida de cada enfermeiro(a). A menina que cresce submetida a um processo educacional diferencial entre homem e mulher, tendo interiorizado os papeis passivos que the impuseram, dificilmente deixara de repeti-los com comportamentos estereotipados na vida profissional representados por obediência, pouca politização, etc. Não queremos de forma alguma radicalizar esta idéia mas 
tampouco nos alienarmos à sua existência.

$\mathrm{MARX}^{2 !}$ já dizia:

"Não é a consciência dos homens que determina o seu ser mas, ao contrário, é o seu ser social que determina a consciência".

BEAUVOIR ${ }^{5}$ relata que

"a discriminação existente em relação d̀s minorias, em especial contra o sexo feminino, aparece porque as mulheres nunca formaram uma sociedade autônoma e fechada; elas fazem parte de uma colelividade governada por homens e na qual ocupam o lugar de subordinadas".

MARTINS ${ }^{20}$ refere que, historicamente, a classe que exerce a dominação tem sido aquela que possui os meios de produção. Para isso se utiliza de um poder coercitivo e uma força ideológica, representados pelo aparato do Estado e pela hegemonia. A resistência da classe dominada à exploração e a defesa dos seus interesses proprios leva ao antagonismo que se configura nas lutas entre as classes, à existência de forças sociais que se contrapõem e que estabelecem a dinâmica que elabora a história. No momento que a(o) Enfermeira(o) busca definir seu papel social, ela(e) deve buscar compreender o local que ocupa, as possibilidades e limitações que a estrutura social the impõe. Esta teoria, por ser a que melhor explica os mecanismos sociais de dominação/subordinação, ajuda a(o) Enfermeira(o) a compreender a dialética das instituições onde ela(e) atua, e no desmascaramento das ideologias dominadoras.

Por outro lado, a enfermagem atual vive uma situação de crise séria e que vem se agravando dia-a-dia, representada subjetivamente pela indefinição sobre o que é enfermagem e objetivamente por:

- elevada evasão dos cursos de enfermagem;

- abandono da profissão apos um a dois anos de trabalho;

- pouca participação nos movimentos de classe e com a classe, sejam eles políticos ou culturais;

- pouca motivação para executar um trabalho de qualidade, etc.

As causas desta crise também são muitas, mas podemos citar algumas:

- má utilização dos recursos humanos de enfermagem e escassez dos mesmos;

- $\quad$ política salarial inadequada incapaz de atrair e reter enfermeiras;

- escolas mal instaladas e laboratórios inadequados;

- carga horária estafante; 
- indefinição do papel e ausência de limites do campo de ação;

- deficiência de estruturas organizacionais que compatibilizem com as

necessidades de trabalho da enfermagem, etc.

Além destas causas e efeitos da crise profissional, gostaríamos de discutir sobre o saber e o fazer da enfermagem.

Segundo ALMEIDA ${ }^{2}$, o saber de enfermagem é um instrumental que "pode ser técnico e científico", para possibilitar o cuidado de enfermagem. Não se adere à realidade do trabalho de enfermagem, carregado de contradiçōes.

Entendo que quando o saber técnico e o saber científico são departamentalizados, há uma tendência na prática em aplicar os "rituais de enfermagem" de forma técnica com procedimentos absolutamente idênticos a sujeitos diferentes, fazendo com que na relação existencial com as pessoas doentes sejam omitidos seus saberes individuais.

Quando predominam a aplicação do conhecimento científico de enfermagem, também isolado, transforma alguns grupos sociais em objetos sociais (clientesm usuários, alunas, etc.) e outros grupos em sujeitos sociais (professoras, enfermeiros, supervisoras, etc.).

Para que esta departamentalização técnico/científica avance é necessário que as ideologias da nova enfermagem se configurem a profissão e incluam as forças da sensibilidade (a aplicação dos cinco sentidos), da afetividade (seres humanos) e da racionalidade (tempo e espaço materiais), o que em sintese significa incluir nos currículos de enfermagem o estudo da dimensão arte, hoje opacificada.

PEREIRA ${ }^{28}$ se aproxima deste posicionamento quando diz que as enfermciras têm demonstrado capacidade cientifica na resolução de muitos problemas, $1 \mathrm{em}$ desenvolvido grande habilidade no manuseio de instrumentos e aparelhos, entretanto, a convivencia conciliadora com as rotinas que desumanizam a assistência revela a falta de confiança em seus próprios recursos de pessoa humana, sensível e capaz de encontrar "o outro" pelos liames da solidariedade.

Em análise da concepção mecanicista da vida, CAPRA ${ }^{10}$, autor de uma visão transformadora da sociedade, coloca que "em virtude da estreita concepção biomédica de doença e dos padrões patriarcais de poder no sistema de assistência à saúde, o importante papel que as enfermeiras desempenham no processo de cura, através do contalo com os pacientes, não é plenamente conhecido".

Gracas a esse contato, as enfermeiras adquirem o conhecimento mais amplo do estado físico e psicologico dos clientes, do que os médicos, mas este é considerado menos importante que a avaliação "cientiffica" do médico baseada em testes de laboratório. 
A enfermagem cientifica moderna está na fase de transição para o paradigma das ciências pós-modernas*, está a exigir uma reflexão coletiva onde as enfermeiras e enfermeiros compreendam que: a nova conflitualidade das ciências está se dando entre os partidários da aplicação edificante e os partidários da aplicação técnica, exigin do uma reflexão global sobre a ciência do período da crise de degenerescência do paradigma das ciências modernas. S ANTOS ${ }^{33}$ enfoca a aplicação edificante como a prioridade da assistência global e não a tếcnica em si, já que a aplicação têcnica visa apenas a ação imediata, sem dar margem a argumentação por parte de quem a recebe.

Finalizando, o papel da mulher enfermeira está sofrendo inúmeras modificações que com o decorrer do tempo introjetam mudanças na sua ação, na conquista de seu espaço social e político, o que refletirá em todos os âmbitos de suas relações, garantindo para as futuras gerações de mulheres e homens um convívio mais rico, igualitário e com menos discriminação.

PADILHA, M.I.C. de S. The woman/nurse in the familiar and public aspects - a study contextual-theoretic. Rev.Esc.Enf.USP, v.29, n.3, p. 246-60, dec. 1995.

The study deals with the historical evolution of the woman in the society particularly in the familiar and public aspects. The intention to stablish the relation, over the years, between the woman role and the uursing, a predominant female profession.

UNITERMS: Nurses role. Womans-Nurses. Woman-History.

\section{REFERÊNCIAS BIBLIOGRÁFICAS}

1. ALCÂNTARA, Glete. A Enfermagem moderna como categoria profissional, obstáculos à sua expansão na sociedade brasileira. Ribeiráo Proto, USP - Escola de Enfermagem de Ribeirăo Preto, 1966.

2. ALMEIDA, Maria (ecilia Puntel de; Ro(CHA, Juan S. Yazille. O Saber de enfermagem e sua dimensão prática. Sro Paulo, Cortez, 1986.

3. BADINTER, Elisabeth. Um é o outro. Rio de Janeiro, Nova Fronteira, 1986.

4. BARNES, Elisabeth. As relacoes humanas no hospital. Coimbra, Livraria Almedina, 1973 ,

5. BEAUVOIR, Simone de. OSegundo sexo: a experiéncia vivida. Rio de Janeiro: Nova Fronteira, 1980. v.1.

6. BEAUVOIR, Simone de. () Segundo sexo, a experiência vivida. Rio de Janeiro, Nova Fronteira, 1980, v.2.

7. BELOTTI, Elena Gianini. Educar para a submissăo. 6.ed. Petrópolis, Vozes, 1987. 
8. BI $A Y$, Eva. Trabalho industrial X trabalho doméstico: a ideologia no trabalho feminino. Cad.Pesq. n. 15, p. 8-80, 1995.

9. BRASll, Ministério da Saúde. Secretaria de Documentação. Conferencia Nacional de Saúde e Direitos da Mulher. Brasília, 1986.

10. CAPRA, Fritjof. () Ponto de mutaçio, a ciência, a sociedade e a cultura emergente. São Paulo, Cultrix, 1982.

11. CARVALHO, Vilma de ; CASTRO, Ieda Barreira e. Reflexoes sobre a prática de enfermagem. In: CONGRESS() BRASILEIR() DE ENFERMAGEM, $31^{\circ}$. Fortaleza, 1979. Anajs Fortaleza, ABen/Ce., 1979. p.132-143.

12. D'ÁVILA NETO, Maria Inácia. O autoritarismo e a mulher: o jogo da dominaça machofêmea no lirusil. Rio de Janeiro, Achiamé, 1978.

13. DI LASCIO, Cecília Maria Domenixa Sanioto. O papel social do enfermeiro: realidade e perspectiva de mudança.In: CON(aRESS() BRASILFIRO DE ENFERMAGEM. $34^{\circ}$. Porto Alegre. 1982. Anais, P'orto Alegre, AREn/RS, 1982. p.55-60.

14. ENGELS, Friedrich. A origem da família, da propriedade privada e do estado 4.ed. Săo Paulo. Global, 1989.

15. FOUJAULT, Michel. Microfisica do poder 2. ed. Rio de Janeiro, Graal, 1981.

16. GERMANO, Raimunda Medeiros. Educacão e ideologia da enfermagem no Brasil. São Paulo, Cortez, 1984.

17. LYOTARD, Jean-François. () Pós-moderno. 3.ed. Rio de Janeiro, José Olympio, 1988.

18. MACHI)(), José Rivair. A mulherna idade média. Sao Paulo, Contexto, 1990.

19. MACHADO, Maria Helena. A mão-de-olora feminina no setor saúde no Brasil In:LABRA, Maria Eliana. Mulher, Saúde e Sociedade no Brasil. Petrópolis, Vozes, 1989. p.122.

20. MARTINS, A.A. A Enfermagem e a prática social. Rev. Bras.Enf, v.40, n. 2/5, p. 132 $143,1987$.

21. MARX, Karl. Elementos Fundamentais para la Crítica de la Economia Política. Buenos Aires, Siglo XXI, 1971, p.129.

22. MEL, Victor Hugo de. Evoluçăo histórica da obstetrícia: a marginalidade social das parteiras e da mulher. Belo llorizonte, 1983 p. Dissertação (Mestrado)-Faculdade de Medicina. Universidade Federal de Minas Gerais.

23. MIRANDA, Glaura V. de. () papel social da mulher e sua influência na saúde. A condiçăo social da mulher na so cieclade brasileira.In: CONGRESSO BRASILEIRO DE ENFERMAGEM. 36 $6^{\circ}$. Belo Horizonte. 1984. Anais. Belo Horizonte, ABEn/MG, 1984. p.69-75. 
23. MIRANDA, Glaura V. de. O papel social da mulher e sua influência na saúde. A condiçăo social da mulher na sociedade brasileira.In: CONGRESSO BRASILEIRO DE ENFERMAGEM, 36 , Belo Horizonte, 1984. Anais. Belo Horizonte, ABEn/MG, 1984. p.69-75.

24. MURARO, Rose Marie. Sexualidade da mulher brasileira: corpo e classe social no Brasil. 2.ed. Petrópolis, Vozes, 1983.

25. NASH, Rosalind. Im esboco da vida de Florence Nightingale. Rio de daneiro, Escola de Enfermagem Ana Neri, 1980 (mimeografado).

26. NIGHTINGALE, Florence. Notas sobro enfermagem. Sao Paulo, Cortez, 1983.

27. P'AIXÃO, Waleska. História da enfermagem. 5.ed. Rio de Janeiro, Júlio C. Reis Livraria, 1979.

28. PHRELRA, Araci Carmen. (G "Ethos" da enfermagem: aspectos fenomenologicos para fundamentação da deontologia de enfermagem. Rio de Janeiro, 1981, 125p. Dissertaçao (Mestrado). Universidade Gama Filho.

29. PIRES, Denise. Hegemonia médica na saúde e a enfermagem. São Paulo, Cortez, 1989.

30. PRAD(), Danda. Ser esnosa: a mais antiga profissăo. Sao Paulo, Brasiliense, 1979.

31. ROGERS, Natalie. A mulher emergente uma experiencia de vida 4ed., São Paulo, Martins Fontes, 1987.

32. SAFFIOTI, Heleith I.H. Do artesanal no industrial A exploraça da mulher. Sxo l'aulo, Hucitec, 1981.

33. SANTOS, Boaventura Souza. Introdução a uma ciéncia pós-moderna. Rio de Janeiro, Graal, 1989.

34. SANTOS, Isabel;VIEIRA, César Augusto Barros de. Análise crítica da prática atual da enfermagem no país. In: (ONGRESSO BRASILEIRO D)E ENFERMAGEM, 31 ", Fortaleza, 1979. Anais. Fortaleza ABEn. 1979, , 85 .

35. SILVA, Graciete Borges da. Enfermagem profissional: análise crítica. Sao Paulo, Cortez, 1986 .

36. SOUZA, Elvira de F. Manual de técnica de enfermageem, 49.ed. Rio de daneiro, Bruno Buccini, 1966.

37. WIT, Cynthia. La ideologia de la revolucion cientifica y sus implicaciones en la ingenieria reproductiva y genética. Caderno Salud Mujeres, v.2, p.72, 1987. 